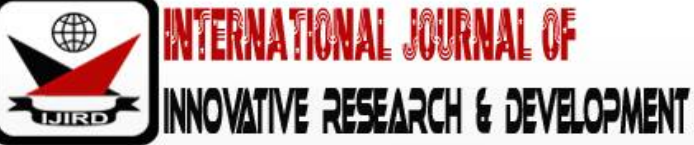

ISSN 2278 - 0211 (Online)

\section{Effect of Respiratory Physiotherapy in Preventing Pulmonary Complications in Post CABG: A Cross-Sectional Study at LUH Hyderabad, Pakistan}

\author{
Victoria Samar
Senior Lecturer, People's Nursing School, Liaquat University of Medical and Health Sciences, Pakistan \\ Dr. Rohama Samar \\ Trainee (FCPS-II), Department of Internal Medicine, Aga khan University Hospital, Pakistan \\ Dr. Sara Samar \\ M. Phil Scholar, Department of Immunology, University of Health Sciences, Pakistan
}

\begin{abstract}
:
Background: The efficacy of physiotherapy techniques used for patients following uncomplicated coronary artery bypass graft (CABG) surgery is well documented. According to previous literature some of the evident techniques were adopted into practice by cardiothoracic nurses.

Aims and objectives: The aim of this study was to identify the current physiotherapy interventions used for following uncomplicated CABG surgery patients, and to establish the currently evidence-based practice in nursing staff for CABG surgery patients in cardiothoracic ward.

Methods: Using purposive sampling the structured questionnaire was distributed among 10 nurses working in the cardiac ward with response rate $100 \%$.

Results: The results of the study revealed that most common postoperative pulmonary complications in cardiothoracic ward were pleural effusion (90\%), pulmonary embolism (60\%), pneumothorax (50\%) and acute respiratory syndrome (40\%). The routinely physiotherapy techniques which were used to prevent from postoperative pulmonary complications were chest physiotherapy (90\%), splinting while cough (80\%), and incentive spirometry (50\%).

Conclusion: In conclusion nurses used physiotherapy techniques for treating patients following uncomplicated CABG patients such as chest physiotherapy, splinting while cough and incentive spirometry that are supported by the available evidence. This survey provides an insight into physical therapy practice cardiothoracic surgery nurses. Standardized guidelines may be required for nurses to practice better according to clinical care pathway.
\end{abstract}

Keywords: Physiotherapy, effective, CABG, cardiothoracic surgery

\section{Introduction}

Physiotherapy is offered to patients undergoing cardiac surgery ${ }^{1}$. Physical therapy and breathing are recommended to patients after CABG and other cardiac surgeries in Pakistan. One of the greatest opportunities for patients with cardiac problem is that the cardiac surgery unit Liaquat University Hospital Hyderabad providing a great facility. In this unit cardiac patients are observed for both pre and post-operative care. The aim of this survey was to establish the current practice of physical therapy for cardiac surgery patient. To prevent post- operative complications, pre- operative physiotherapy is also recommended to cardiac patients at home or hospital stay2. The physiotherapy consist mobilization, range of motion exercises and breathing exercises. Patients actually should be mobilized and exercised during the $1^{\text {st }}$ day after surgery. Post-operative complications are more common in CABG patients ${ }^{3}$. The cause of complication is involving the contribution of various factors such as general anesthesia, diaphragmatic dysfunction, abdominal distension, chest wall, alteration, pleural effusion, pneumothorax and severe pain. Post- surgery physiotherapy programs are aimed to reduce the risk of post-operative pulmonary complications due to long stay on bed, to improve the quality of life residual function ${ }^{4}$. Strategies to reduce post - operative cardiac surgery complications include monitoring and reduction of risk factors improving pre - operative status, patient's education and post - operative pulmonary care 5 . In Pakistan most of the hospitals are offering physiotherapy like IPRS, LUMHS, cardiac rehabilitation program (AKUH) and Isra University Hospital of physiotherapy are included. The aim of these hospitals to reduce the risk of cardiac disease including pleural effusion, pneumothorax and postural hypotension, and providing exercises strategies, health education and health information about these problems. These institutes are providing health information about some home remedies such as exercise, yoga and meditation for those patients who have excessive stress due to cardiac problem.

Heart surgery is associate with pulmonary complication is relative to postoperatively and serious post-operative pulmonary complication is that pneumonia, respiratory failure, fever and some complication related to mechanical 
ventilation such as plural effusion, pneumothorax and pulmonary edema ${ }^{6}$. The study conducted to reduce the post-surgery pulmonary complication with the help of pre-surgery respiratory physiotherapy and exercise routine involving incentive spirometry, deep breathing exercise and coughing. In this physiotherapist check and observe respiratory strength muscles weakness and also identify the smoking habits. Recently in pre-surgery CABG patient found that incentive spirometry muscles training ( 7 times a week for at least 2 weeks before the surgery) will reduce the high risk of pulmonary complication and decrease the post hospital stay. Constantia Lomi et.al 2013, patient should perform the breathing exercise 1-4 times in a day, 1st or 2-day post operatively during the first 5 days, post- operative patients received 1-6 physiotherapy session by physiotherapist. This session will help to reduce the post-operative pulmonary complication and giving positive sign of successful surgery6. Physical activity is important for all individual and especially beneficial for those individual already diagnose Chronic Heart Failure. Individual with heart disease should understand that a constant exercise program is a part of the management for their disease and is as necessary for as their medication. During the time of surgery, the effect of decrease activity can be divesting, therefore the relative energy cost of all activity increased and heart actually work harder for any given task ${ }^{7}$. For patients who have had bypass surgery (e.g. CABG) recovery is somewhat slower than normal. The number and location of incision depend on the surgeon's techniques (i.e. a full sternal cut, partial sternal cut or intercostal cut approach) ${ }^{8}$. Sternal precautions are commonly applied to dehiscence of the incision. Cited risk factors for dehiscence include diabetes pendulous breasts, obesity and Chronic Obstructive Pulmonary Disease (COPD). Sternal precautions vary greatly by the physician instruction and type of surgery performed. Instructions may include limiting lifting of objects between 5 and 10 pounds for up to 8 weeks after surgery. It is important to develop a professional collegial relationship with the surgical team ${ }^{9}$. To avoid sternal discomfort all patient will benefit from splinting the incision with the hand or pillow when laughing, coughing \& sneezing. During the initial weeks following cardiac surgery the early in hospital limitation following cardiac surgery have perhaps more to do with the surgical procedure and altered mobility. Postoperative fatigue may be due to a combination of factors including anesthesia, blood loss. The patient is encouraged to gradually increase walking with a goal of 30 minutes of ambulation 1 to 2 times per day at 4 to 6 weeks after surgery. Once a patient's incision has healed (approximately 6 weeks), and his or her blood counts include hematocrit and hemoglobin are in ranges ${ }^{8}$.

\section{Material and Methods}

A cross sectional descriptive study was undertaken to examine the physical therapy of adult CABG patients at cardiothoracic surgery Liaquat University Hospital (LUH) Hyderabad. A questionnaire was constructed for this study. All staff nurses $(n=10)$ working at cardiothoracic surgery were participated in this study. The questionnaire was addressed personally to the 10 staff nurses thus identified after agreeing on written consent. The permission was also granted from the head of the cardiothoracic surgery department. The questionnaire is consisted of 10 close ended questions inquiring about physiotherapy care of patients undergoing CABG surgery (see table 1). The study was descriptive cross sectional therefore the data of the study is expressed in the form of frequency and percentage with the help of charts.

\begin{tabular}{|l|c|}
\hline \multicolumn{1}{|c|}{ Question } & Options to Answer \\
\hline $\begin{array}{l}\text { Q.1: - Are all CABG patients assessed pre-operatively } \\
\text { for post- operative pulmonary complications? }\end{array}$ & $\begin{array}{c}\text { a. Yes } \\
\text { b. No }\end{array}$ \\
\hline Q2: - Are all CABG patients assessed post-operatively \\
for post -operative pulmonary complications? & a. Yes \\
b. No
\end{tabular}

Table 1: Questionnaire of the Study 


\section{Result}

The response rate from the participants was $100 \%$. The majority of respondents $(n=10,90 \%)$ reported that all the CABG patients undergoing surgery are assessed preoperatively, whereas 1 respondent (10\%) reported that patients are not assessed preoperatively. CABG patients are assessed postoperatively said by six respondents (60\%), whereas four respondents said that CABG patients are not assessed postoperatively. Four respondents (40\%) reveal that average length of postoperative stay for undergo uncomplicated CABG surgery is approximately 1-2 weeks, whereas six respondents $(60 \%)$ reveals that average length of stay is not 1-2 weeks. Half of the respondents $(50 \%)$ indicated that in their ward postoperative management of patients was not done by guided clinical care pathway, whereas $50 \%$ respondent indicate that they done postoperative care by guided clinical care pathway. 50\% of participants reported that they did not review postoperative CABG patients for any complication.

A range of physiotherapy treatment was utilized routinely on uncomplicated CABG patients, chest physiotherapy was performed by (90\%) respondents, (80\%) of respondent reported that they implemented splinting while coughing in CABG patients, incentive spirometry was utilized by (50\%) respondents, progressive mobilization was implemented by (40\%) respondents. Half of the respondents (50\%) reported that upper limb and rang trunk of motion exercise can be performed, and $40 \%$ respondents revealed that patient sat out of bed technique was used. $(40 \%)$ respondents $(n=4)$ indicated that they start physiotherapy within 24 hours, 6 respondents $(60 \%)$ reported that they recommend home exercise to the post-operative CABG patient at the time of discharge from hospital.

When it was asked from nurses that what type of pulmonary complications can occur after CABG surgery, they indicate that following complications (fig; 2) can occur which includes; pleural effusion (90\%), pulmonary embolism $(60 \%)$, pneumothorax (50\%), diaphragmatic paralysis (40\%), acute respiratory syndrome (40\%), atelectasis (30\%) and pneumonia (20\%).

\begin{tabular}{|l|c|c|}
\hline \multicolumn{1}{|c|}{ Question } & & N=10(\%) \\
\hline $\begin{array}{l}\text { Q.1: - Are all CABG patients assessed pre-operatively for post- operative } \\
\text { pulmonary complications? }\end{array}$ & a. Yes & $9(90)$ \\
b. No & $1(10)$ \\
\hline $\begin{array}{l}\text { Q2: - Are all CABG patients assessed post-operatively for post -operative } \\
\text { pulmonary complications? }\end{array}$ & a. Yes & $6(60)$ \\
\hline Q.3: - The average length of post-operative stay for patients undergo & a. Yes & $4(40)$ \\
uncomplicated CABG surgery is approximately 1-2 weeks? & b. No & $6(40)$ \\
\hline Q.4: - Are all CABG patients routinely assessed for pulmonary complication? & a. Yes & $8(80)$ \\
\hline Q.5: - Is the post-operative management of patients undergoing uncomplicated & b. No & $2(20)$ \\
CABG surgery in your unit, guided by clinical care pathway? & b. No & $5(50)$ \\
\hline Q.6: - Do you review post-operative CABG patients any complication? & a. Yes & $5(50)$ \\
\hline $\begin{array}{l}\text { Q.07: In routine CABG patients, following interventions do you routinely } \\
\text { incorporate in your treatment program? }\end{array}$ & b. No & $5(50)$ \\
\hline Q.8: - Do you start post-operative physiotherapy within 24 hours? & b. No & $9(90)$ \\
& a. Yes & $4(10)$ \\
\hline Q.9: - Do you recommend home exercise at the time of discharge? & b. No & $6(60)$ \\
\hline
\end{tabular}

Table 2

\begin{tabular}{|c|c|}
\hline Physiotherapy Interventions Used & Percentage \\
\hline Chest physiotherapy & $90 \%$ \\
\hline Splinting while cough & $80 \%$ \\
\hline Incentive spirometry & $50 \%$ \\
\hline Upper limb and range trunk of motion exercise & $50 \%$ \\
\hline Progressive mobilization & $40 \%$ \\
\hline Sitting out of bed & $40 \%$ \\
\hline
\end{tabular}

Table 3: Physiotherapy Interventions Used by Nurses for CABG Surgery Patients

\begin{tabular}{|c|c|}
\hline Pulmonary Complications & Percentage \\
\hline Pleural effusion & $90 \%$ \\
\hline Pulmonary embolism & $60 \%$ \\
\hline Pneumothorax & $50 \%$ \\
\hline Diaphragmatic paralysis & $40 \%$ \\
\hline Acute respiratory syndrome & $40 \%$ \\
\hline Atelectasis & $30 \%$ \\
\hline Pneumonia & $20 \%$ \\
\hline
\end{tabular}

Table 4: Pulmonary Complications which Occur in Cardiothoracic Surgery Ward If Interventions Not Done 


\section{Discussion}

The result of this study shows that some aspects of physiotherapy management of uncomplicated CABG patients in cardiothoracic surgery ward LUH Hyderabad may bases on currently available evidence. In our present study $90 \%$ respondents showed that they asses the CABG patients preoperatively for pulmonary complications, and $60 \%$ respondents showed that they asses the CABG patients postoperatively for pulmonary complications. Literature indicates that pre and postoperative assessment is important, in this therapist check and observes respiratory muscles strength and weakness and also identify the lifestyle 10,11 .According to $40 \%$ respondents the average stay period of postoperative CABG patients is up to $1-2$ weeks in hospital, whereas $60 \%$ reported that it may be longer than 2 weeks. In this period, they implement the physiotherapy treatment, and majority of respondents reported that they start physiotherapy session after 24 hours (1day).Thus, it is identified from literature that CABG or other cardiac surgery patients should have stay for longer postoperative time because the recovery of these patients is slower than normal. Today there is an agreement as to value of the early mobilization after cardiac surgery ${ }^{12}$. After cardiac surgery the cardiovascular status of the patient is one factor that helps to decide the intensity of mobilization. Almost some respondent in our study mobilize the patients in first preoperative days ${ }^{12}$.

Our study shows that the most frequently maneuvers used for CABG surgery patients are chest physiotherapy (90\%), splinting while cough (80\%), incentive spirometry (50\%), upper limb and range trunk of motion exercises $(50 \%)$, progressive mobilization (40\%), and sitting out of bed (40\%). This finding suggests that the ability to identifying relevant literature does ensure the application of literature recommendation to current practice. Thus, the literature reveals that patient should perform the exercises (incentive spirometry, breathing exercise, mobilization, chest physiotherapy and sitting out of bed) 1-4 times on the 1st or $2^{\text {nd }}$ postoperative day; it will help to reduce the postoperative pulmonary complication and giving positive sign of successful surgery ${ }^{13}$.

This study shows that the most common postoperative pulmonary complications in cardiothoracic wad were pleural effusion $(90 \%)$, pulmonary embolism $(60 \%)$, pneumothorax (50\%), diaphragmatic paralysis (40\%) and acute respiratory syndrome $(40 \%)$, and the postoperative complications which were rare in range were atelectasis $(30 \%)$ and pneumonia (20\%).A clinical care pathway implemented by 50\% of respondents in the current study is a method of standardized and improving patient care and lowering health cost $^{14}$. Their motives for the implementation of a care pathway were its ability to facilitate the consensus of best practice among health professional promoting consistency ${ }^{14}$. However, our study shows that half of the respondents (50\%) did not follow a clinical care pathway. This study shows that in cardiothoracic surgery ward $60 \%$ of staff nurses recommend home exercise to the CABG patients at the time of discharge. Physical exercise is important for all postoperative CABG patients, they should have to understand that exercise program is a part of the management for their disease and is necessary for their as their medications².

\section{Conclusion}

This survey provides an overview of current physical therapy practice for CABG surgery patients in cardiothoracic surgery ward. This study shows that they routinely asses and look after the CABG patients. The most common postoperative pulmonary complications are pleural effusion, pulmonary embolism, pneumothorax, diaphragmatic paralysis and acute respiratory syndrome. The routinely used of physiotherapy techniques to prevent from these complications are chest physiotherapy, splinting while cough, incentive spirometry, upper limb and range trunk of motion exercises and mobilization, while the most frequently used techniques were chest physiotherapy (90\%) and splinting while cough (80\%).It is worst that half of the nurses in this ward show that they did not follow clinical care pathways to providing physiotherapy care to patients. In several countries physical therapy is routinely offered after cardiac surgery. There are various treatment options and opinion about the best way to treat the patients, and this survey provides an insight into the physical therapy practice in cardiothoracic surgery LUH.

\section{References}

i. Fatima R. Pre and post-operative physiotherapy for patients after open heart surgery. European International Journal of Science and Technology; 2017; 6(2); ISSN: 2304-9693

ii. Roos R, \&Aswegan V. physiotherapy management of patients with coronary artery disease: A report on current practice in South Africa. SA Journal of Physiotherapy; 2011; 67(1); 4-8.

iii. Dar MI, Dar AH, Almani K, Attaul-mannan, Khan AQ, Rizwani GH \& Ahmad M. Coronary artery bypass surgery in old age group: Is age itself a barrier? JPMA; 2009; 59; 587.

iv. Sher-i-Murtaza M, Baig MAR, Raheel HMA. Early outcome of Coronary Artery Bypass Graft Surgery in patients with significant Left Main Stem stenosis at a tertiary cardiac care center. Pak J Med Sci; 2015; 31(4):909-914. doi:http:/ / dx.doi.org/ 10.12669/ pjms.314.7597

v. Qiang Ji, Yunqing Mei, Xisheng Wang, Jing Feng, Jianzhi Cai, \&Wenjun Ding. Risk factors for pulmonary complications following cardiac surgery with cardiopulmonary bypass. International Journal of Medical Sciences; 2013; 10(11):1578-1583. doi: 10.7150/ ijms.6904

vi. Yánez-Brage I, Pita-Fernández S, Juffé-Stein A, Martínez-González U, Pértega-Díaz S \& MauleónGarcía A. Respiratory physiotherapy and incidence of pulmonary complications in off-pump coronary artery bypass graft surgery: an observational follow-up study. Bio Med Central; 2009; 9; 36; doi:10.1186/ 1471-2466-9-36.

vii. Moreno AM, Castro RRT, Sorares PPS, Anna MS, Cravo SLD \& Nóbrega ACL. Longitudinal evaluation the pulmonary function of the pre and postoperative periods in the coronary artery bypass graft surgery of patients treated with a physiotherapy protocol. Journal of Cardiothoracic Surgery;2011; 6:62. 
viii. Shakouri SK, Salekzamani Y, Taghizadieh A, Sabbagh-Jadid H, Solemani J, Sahebi L, \& Sahebi R. Effect of respiratory rehabilitation before open cardiac surgery on respiratory function: a randomized clinical trial.J Cardiovasc Thorac Res; 2015; 7(1); 13-17. doi: 10.15171/jcvtr.2014.03

ix. Saleh HZ; Mohan K, Shaw M, Al-Raw O, Elsayed H, Walshaw M, Chalmers JAC \& Fabri BM. Impact of chronic obstructive pulmonary disease severity on surgical outcomes in patients undergoing non-emergent coronary artery bypass grafting. European Journal of Cardio-Thoracic Surgery; 2012; 42; 108-113. doi:10.1093/ ejcts/ ezr271

x. Cavenaghi S, Ferreira LL, Marino LHC, LamariRev NM. Respiratory physiotherapy in pre and postoperative myocardial revascularization surgery. Bras Cir Cardiovasc; 2011; 26(3):455-61. DOI: 10.5935/16789741.20110022.

xi. Monisha R, Amutha k1 and Aparna Krishnakumar. Effica of TENS and Respiratory Physiotherapy to Improve Functional Capacity in Post CABG Patient. Journal of Physiotherapy Research; 2017; 1(2)8.

xii. Filbay SR, Hayes K, \& Holland AE. Physiotherapy for patients following coronary artery bypass graft (CABG) surgery: Limited uptake of evidence into practice. Physiotherapy Theory and Practice; 2011; DOI: 10.3109/ 09593985.2011.582231

xiii. Lomi C \& Westerdahl E. Physical Therapy Treatment after Cardiac Surgery: A National Survey of Practice in Greece.J Clin Exp Cardiolog: 2013; 004. doi: 10.4172/ 2155-9880.

xiv. Makhabah DN, Martino F \& Ambrosino N. Peri-operative physiotherapy. Multidisciplinary Respiratory Medicine;2013; 8:4 